\title{
Oral health-related quality of life of a consecutive sample of Spanish dental patients
}

\author{
Javier Montero ${ }^{1}$, José-María Yarte ${ }^{2}$, Manuel Bravo ${ }^{3}$, Antonio López-Valverde ${ }^{4}$ \\ ${ }^{1}$ Tenured lecturer of Prosthodontics. Department of Surgery. Faculty of Medicine. University of Salamanca. Spain \\ ${ }^{2}$ Dentistry Degree. University of Salamanca. Spain \\ ${ }^{3}$ Professor of Community and Preventive Dentistry. University of Granada. Spain \\ ${ }^{4}$ Associate Professor. Department of Surgery. Faculty of Medicine. University of Salamanca. Spain
}

Correspondence:

Clínica Odontológica

Facultad de Medicina

C/ Alfonso X el Sabio s/n

Campus Miguel de Unamuno

37007. Salamanca. Spain

]avimont@usal.es

\author{
Montero J, Yarte JM, Bravo M, López-Valverde A. Oral health-related \\ quality of life of a consecutive sample of Spanish dental patients. Med \\ Oral Patol Oral Cir Bucal. 2011 Sep 1;16 (6):e810-5. \\ http://www.medicinaoral.com/medoralfree01/v16i6/medoralv16i6p810.pdf

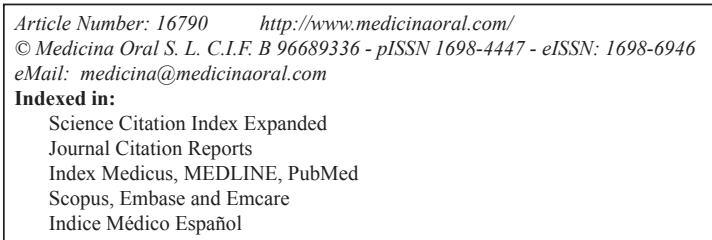

Received: 06/02/2010

Accepted: 21/03/2010

\begin{abstract}
Objectives: Assessment of the oral health-related quality of life and the modulating factors of patients deman-ding dental treatment in the city of Salamanca, through the use of two validated instruments: the OIDP-sp (Oral Impacts on Daily Performance) and OHIP-14 (Oral Health Impact Profile).

Study design: the study was conducted on a consecutive sample of 200 patients aged 18-65 years visiting an Integral Dental Centre in the city of Salamanca. Two validated instruments (OIDP-sp and OHIP-14) were used to measure the oral health-related quality of life. An analogue visual scale was used to register oral satisfaction. Data on sociodemographic background, behavioural and clinical factors were also gathered. ANOVA, T Student Test, and both Pearson and Spearman correlations coefficients were used for the statistical analysis.

Results: according to the OIDP, $68.5 \%$ suffered from some kind of impact in their oral quality of life, while impact prevalence with the OHIP was $85 \%$. Some other factors influencing the quality of life and degree of satisfaction were revealed.

Conclusions: patients over 45 years, regardless of their gender, from high social class, living in rural areas and with poor hygiene, showed higher impact and lower satisfaction. The study also revealed some clinical conditions closely related to the level of satisfaction.
\end{abstract}

Key words: Oral health-related quality of life, satisfaction, self-assessment. 


\section{Introduction}

According to the World Health Organization (WHO), health is not lack of illness but good physical, psychological and social state. The professional can diagnose physical state, but not psychological or social wellbeing, which can only be assessed by the subject through the indicators of oral health-related quality of life (OHRQoL). These indicators of OHRQoL emerged in the 70s in order to evaluate the physical, psychological and social impact that oral pathologies have on the individual and are meant to complement the information provided by clinical indexes, as they are not sensitive to subjective perceptions such as pain, aesthetics, functionality, etc (1).

The last National Survey on Oral Health of 2005 (2), confirmed that more than a third of adults and the elderly had occasionally or more frequently suffered from oral impacts (dental pain or eating limitation), in the 12 months prior to the survey. However, as these subjects were not seeking dental treatment because of the type of sampling, the impact figures are likely to increase in dental patients. As far as we know, the impact of OHRQoL in patients demanding dental treatment has not been evaluated in our country, although it has been assessed in the general population (3), evidencing a moderate to high oral impact of the Spanish adults. However in other countries it has already been stated that the main causes of impact for dental visits are related to toothache (4).

The OIDP (Oral Impacts on Daily Performance) (5) and the OHIP (Oral Health Impact Profile) (6), are two of the most reliable indicators when it comes to establish the OHRQoL; they are both based on the Locker model of oral health (7) and have been previously validated among the Spanish population $(3,8)$. That is the reason behind the decision of using both indicators to measure the impact in the OHRQoL in dental patients.

\section{Material and Methods}

A consecutive sample of dental patients $(n=200)$ aged 18-65, who attended a Dental Office in the City of Salamanca were clinically examined for caries and periodontal disease following the criteria proposed by the WHO Basic Methods for Oral Health Surveys in 1987, once given informed consent. We also registered by inspection some prosthodontic conditions as number of standing teeth, oclussal units, replaced teeth and replaceable teeth (prosthetic space preserved). But foreseeing that visible impairments would not have the same impact as those invisible, the dental arch was divided in two regions: one visible (from second premolar to second premolar inclusive) and the other invisible (molar sectors).

Data on impact on OHQoL were collected using the OIDP (8) and OHIP-14 (3) questionnaires by a trained interviewer. Socio-demographic data, such as gender, age, residence (urban or rural) and social class (high, middle or low); and behavioural data as frequency of brushing (basic: < twice/day and excellent: $>$ twice/day) and reason of dental visits (regular or problems-related) were also gathered. The reason for the visit was divided in four groups (pain, revision, prosthesis and fillings).

OHQoL Instruments

The OIDP is completed by recording the presence of problems or difficulties in any of their eight dimensions (eating, pronouncing, hygiene, work, social relations, sleeping, smiling and state of mind), evaluating the frequency of appearance and the perceived severity of these impacts through a regular Likert scale. The degree of severity is codified from 0 to 5 , being 0 "zero effect " and 5 "very severe effect", the frequency of appearance from 1 to 5 , being 1 "less than once a week" and 5 "everyday or almost every day". Finally, the cause of the impact on each dimension was established clinically. In order to calculate the total score of the OIDP (OIDP-TOTAL) the frequency and severity of each dimensional impact were multiplied, adding the scores of the eight dimensions and dividing by 200, the maximum total number which can be obtained, having thus an interpretation in percentage terms.

Subjects filled out the OHIP-14, answering in terms of frequency the appearance of 14 situations of impact conceptually divided in 7 dimensions (pain, functional limitation, psychological discomfort, physical disability, mental disability, social disability and handicap). Frequency was codified by using a Likert scale with 5 options (never, hardly ever, occasionally, several times and many times). In order to calculate the total score of the OHIP, the additive method OHIP-AD was used, adding up the scores obtained in the 14 items of the test. The values assigned were: never $=0$, hardly ever $=1$, occasionally $=2$, several times $=3$, many times $=4$. The prevalence of impacts was calculated by using the occasional threshold (score $\geq 2$ ).

In both questionnaires higher total score implies higher level of impact in oral well-being. The degree of oral, aesthetic and masticatory satisfaction was also recorded using a visual analogue scale from 0 to 10 , which had already proved its descriptive validity (8).

\section{Data analysis}

The data were analysed by using the programme SPSS (Statistical Package for Social Sciences, Inc., Chicago, IL), version 15.0. Parametrical tests for the comparison of averages ( $T$ of Student and ANOVA) were used in the comparison of the levels of impact and satisfaction among different groups. Both Pearson and Spearman correlation coefficients were used to assess the effect of some clinical conditions. A p-value $<0.05$ was considered as statistically significant. 


\section{Results}

The sample was drawn mainly from women (63\%), of middle class $(95 \%)$, living in the city of Salamanca $(84.5 \%)$ of an average age between $44.5 \pm 13.4$. In terms of behaviour, the frequency of brushing was excellent in $76.0 \%$ of patients, and $51.5 \%$ of this sample visited the dentist in a regular basis. The main reason for dental visit was preventive revision in $37.7 \%$, while the most prevalent clinical diagnosis was caries in $54.5 \%$ of the subjects.

(Table 1) shows the clinical description of the sample and reflects a good oral health, i.e. almost all teeth in mouth, few decayed teeth, i.e. DMFT (sum of decayed, missing and filled teeth) is on average $9.8 \pm 5.1$; and most of sextants $(3.1 \pm 2.2)$ are healthy $(\mathrm{CPI}=0)$.
In terms of OHRQoL and according to the OIDP, $68.5 \%$ of the subjects had some kind of oral impact, while $62 \%$ of the sample suffered from oral impacts of moderate or higher severity in the last 6 months. The impact of the OHRQoL according to the OHIP, shows that $100.0 \%$ of the sample has undergone some kind of impact, as none of the subjects scored 0 , although only $85.0 \%$ had oral impacts occasionally or more often. Global oral satisfaction was $6.3 \pm 1.2$, being masticatory satisfaction 6.4 \pm 1.6 and aesthetic satisfaction $5.9 \pm 1.2$ (Table 1).

According to the OIDP, the most prevalent dimensions affected were "eating" 36.5\%, "hygiene" $33.0 \%$ and "smiling" $24.5 \%$ (Fig. 1). According to the OHIP (Fig. 2), the main problems were found in "worry about the mouth" (OHIP-5) which occurred occasionally or more

Table 1. Well-being and clinical description of the sample $(n=200)$.

\begin{tabular}{|l|l|}
\hline \multicolumn{1}{|c|}{ Well-being description } & $\begin{array}{c}\text { mean } \pm \text { standard } \\
\text { deviation }\end{array}$ \\
\hline Total OIDP & $5.2 \pm 5.8$ \\
\hline Total OHIP & $9.9 \pm 5.7$ \\
\hline General satisfaction & $6.3 \pm 1.2$ \\
\hline Masticatory satisfaction & $6.4 \pm 1.6$ \\
\hline Aesthetic satisfaction & $5.9 \pm 1.2$ \\
\hline & $\begin{array}{c}\text { mean } \pm \text { standard } \\
\text { deviation }\end{array}$ \\
\hline Visible decayed teeth & $0.5 \pm 1.4$ \\
\hline Visible missing teeth & $0.8 \pm 1.8$ \\
\hline Visible filled teeth & $2.6 \pm 2.4$ \\
\hline Invisible decayed teeth & $0.8 \pm 1.2$ \\
\hline Invisible missing teeth & $1.3 \pm 1.9$ \\
\hline Invisible filled teeth & $3.3 \pm 2.0$ \\
\hline Standing teeth in mouth & $27.9 \pm 3.9$ \\
\hline DMFT (sum of decayed, missing and filled teeth) & $9.8 \pm 5.1$ \\
\hline Teeth in maximum contact & $12.0 \pm 2.3$ \\
\hline Prothetic teeth in mouth & $1.2 \pm 4.1$ \\
\hline Visible teeth candidate of prosthesis & $0.5 \pm 1.1$ \\
\hline Invisible teeth candidate of prosthesis & $0.8 \pm 1.3$ \\
\hline Number of sextants coded as CPI* $=0$ & $3.1 \pm 2.2$ \\
\hline CPI: Con & \\
\hline
\end{tabular}

*CPI: Community Periodontal Index

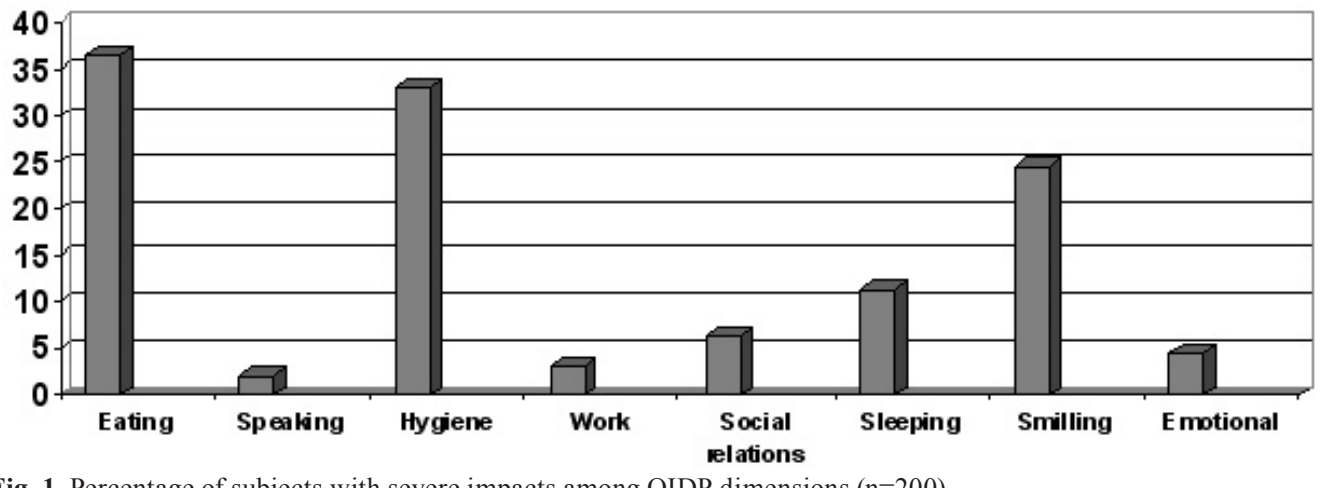

Fig. 1. Percentage of subjects with severe impacts among OIDP dimensions $(n=200)$. 


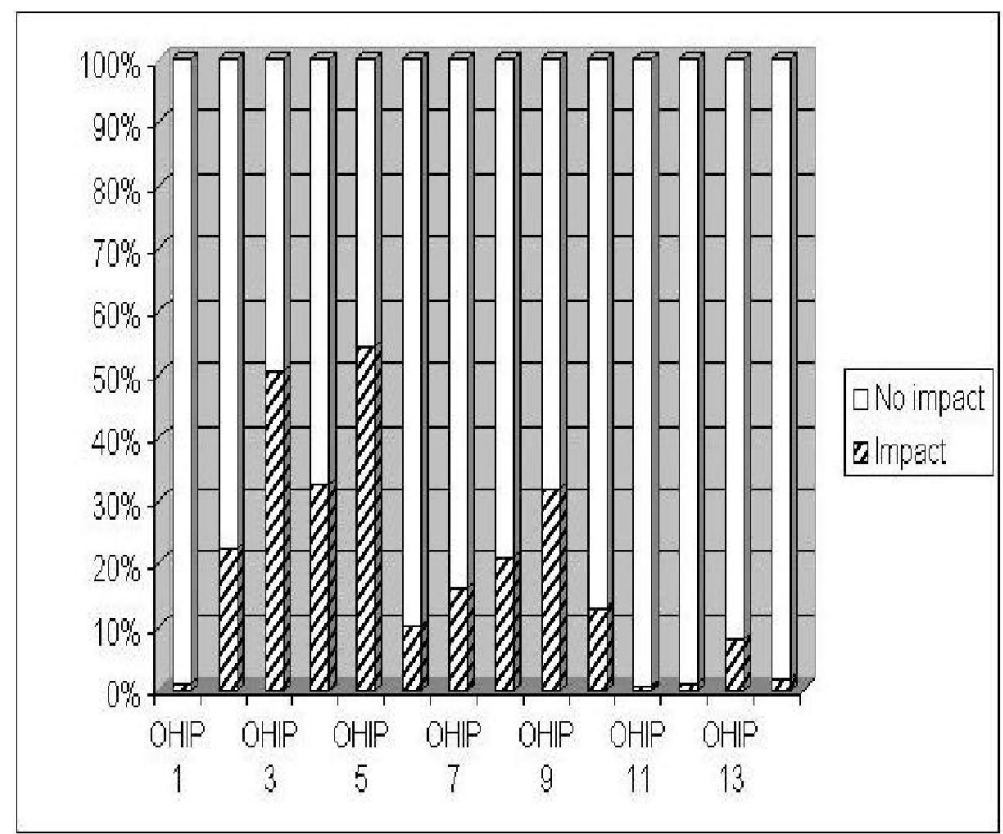

Fig. 2. Percentage of subjects suffering from oral impacts occasional or more frequently ( $\geq 2)$ among OHIP-14 items ( $\mathrm{n}=200)$.

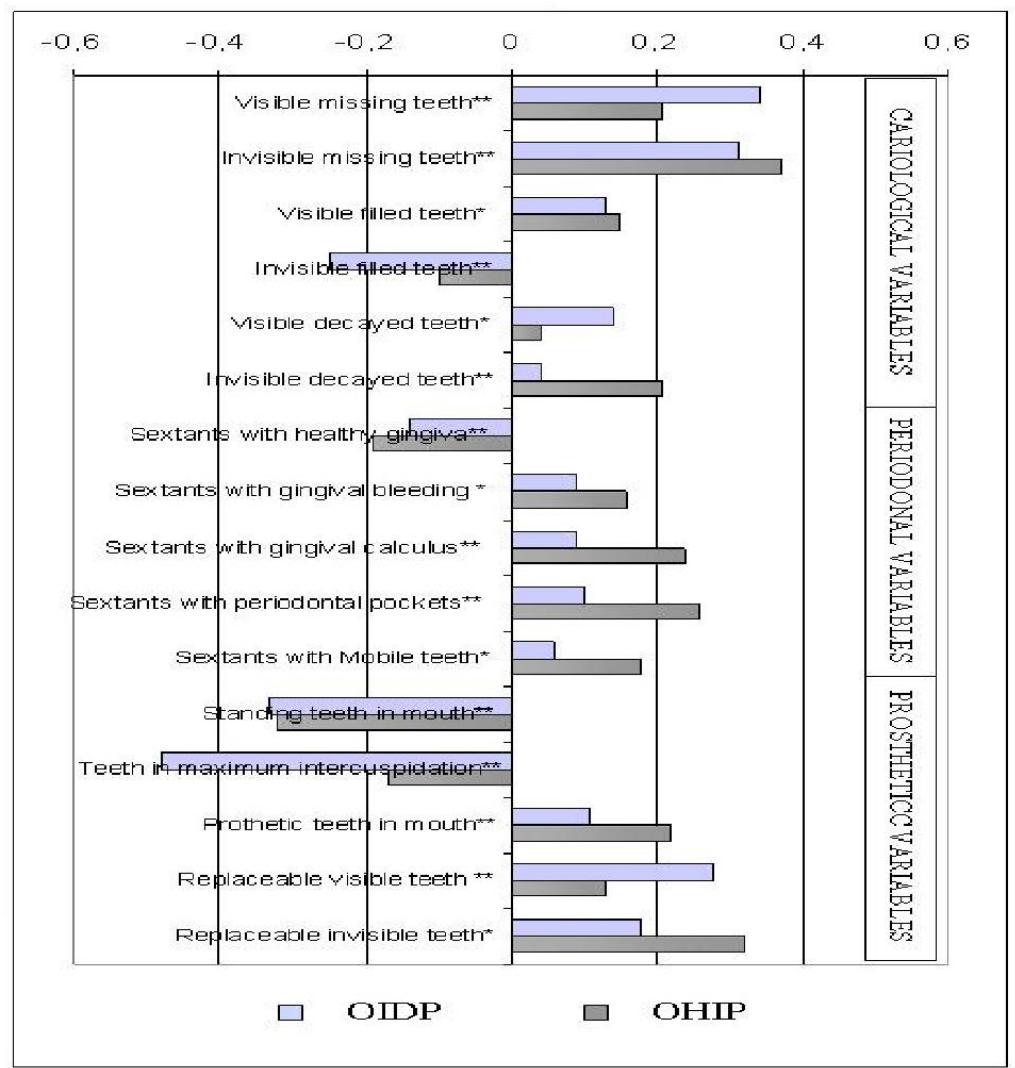

Fig. 3. Pearson Correlation Coefficients between clinical variables and total scores of OIDP and OHIP. *: $\mathrm{p}<0.05 . * *: \mathrm{p}<0.01$. 
Table 2. Modulating factors of the OHRQoL in dental patients.

\begin{tabular}{|c|c|c|c|c|c|}
\hline \multicolumn{2}{|c|}{$\begin{array}{l}\text { SOCIODEMOGRAPHIC } \\
\text { FACTORS }\end{array}$} & $\begin{array}{l}\text { OIDP-TOTAL } \\
(\text { mean } \pm \text { sd })\end{array}$ & $\begin{array}{c}\text { Comparison } \\
\text { (p-value) }\end{array}$ & $\begin{array}{r}\text { OHIP-AD } \\
(\text { mean } \pm \text { sd) }\end{array}$ & $\begin{array}{c}\text { Comparison } \\
\text { (p-value) }\end{array}$ \\
\hline Gender & $\begin{array}{l}\text { Female } \\
\text { Male }\end{array}$ & $\begin{array}{l}5.3 \pm 4.6 \\
4.8 \pm 6.4\end{array}$ & $\mathrm{p}<0.01$ & $\begin{array}{c}10.4 \pm 6.2 \\
8.9 \pm 4.6\end{array}$ & $\mathrm{p}<0.01$ \\
\hline Age & $\begin{array}{l}\geq 45 \text { years } \\
<45 \text { years }\end{array}$ & $\begin{array}{l}5.5 \pm 6.5 \\
4.6 \pm 4.7\end{array}$ & NS & $\begin{array}{l}11.3 \pm 5.3 \\
8.1 \pm 4.3\end{array}$ & $\mathrm{p}<0.05$ \\
\hline Social class & $\begin{array}{l}\text { High } \\
\text { Middle } \\
\text { Low }\end{array}$ & $\begin{array}{c}12.8 \pm 8.5 \\
4.8 \pm 5.5 \\
9.8 \pm 7.1\end{array}$ & $\mathrm{p}<0.05$ & $\begin{array}{c}11.7 \pm 11.5 \\
9.7 \pm 5.6 \\
13.2 \pm 3.9\end{array}$ & NS \\
\hline Residence & $\begin{array}{l}\text { Urban } \\
\text { Rural }\end{array}$ & $\begin{array}{l}4.7 \pm 5.0^{*} \\
7.1 \pm 8.7^{*}\end{array}$ & $\mathrm{p}<0.05$ & $\begin{array}{c}9.5 \pm 5.4 \\
11.7 \pm 7.0\end{array}$ & $\mathrm{p}<0.05$ \\
\hline \multicolumn{2}{|c|}{$\begin{array}{l}\text { BEHAVIOURAL } \\
\text { FACTORS }\end{array}$} & $\begin{array}{l}\text { OIDP-TOTAL } \\
\quad(\text { mean } \pm \text { sd })\end{array}$ & & $\begin{array}{l}\text { OHIP-AD } \\
(\text { mean } \pm \text { sd })\end{array}$ & \\
\hline Pattern of visits & $\begin{array}{l}\text { Regular } \\
\text { Problems }\end{array}$ & $\begin{array}{l}3.9 \pm 5.4 \\
6.3 \pm 5.9\end{array}$ & $\mathrm{p}<0.05$ & $\begin{array}{c}8.8 \pm 5.5 \\
10.9 \pm 5.8\end{array}$ & $\mathrm{p}<0.05$ \\
\hline Hygiene & $\begin{array}{c}\text { Basic } \\
\text { Excellent }\end{array}$ & $\begin{array}{l}6.8 \pm 6.2 \\
4.6 \pm 5.5\end{array}$ & $\mathrm{p}<0.01$ & $\begin{array}{c}10.5 \pm 5.7 \\
9.6 \pm 5.7\end{array}$ & NS \\
\hline
\end{tabular}

NS: non-significant statistically.

frequently in $54.5 \%$ of the cases, being aesthetics the main reason for that. The second major problem was "pain" (OHIP-3) with 50.5\%, followed by "discomfort when eating" (OHIP-4) in $32.5 \%$, caused mostly by prosthesis and "dissatisfaction with aesthetics" (OHIP-9) in $32.0 \%$ of the cases (Fig. 2).

As for the modulating factors, we found some clinical variables significantly correlated with both OIDP and OHIP total scores (Fig. 3), as number of teeth occluding in maximum intercuspidation, number of standing teeth, visible decayed teeth and periodontal status. Moreover, we also found some sociodemographic and behavioural factors related to the impact on quality of life (Table 2). From the sociodemographic point of view people over 45 have more frequent impacts, although less severe than in the youth, in a statistically significant way, not showing differences of gender. Patients of high social class showed more impact than the other classes using both indicators. The same finding was recorded for rural patients as against urban population. In terms of behaviour, the subjects which go to the dentist with problems have much more impact than those who go regularly. Finally, as far as hygiene is concerned, those with basic oral hygiene had more impact than people with excellent standards. As for the reasons for consultation, we found that patients attending consultation for pain had more impact and less satisfaction than patients who attended for other reasons.

\section{Discussion}

The prevalence of the impact obtained in this study is higher than that obtained by Montero et al. $(3,8)$ in a Spanish general population, but is meaningful as this study is about a population requiring treatment. However, it is remarkable that between 30 and $40 \%$ of the sample admit not having any problem with their mouth despite visiting a dental office. This might be due to the fact that half the people in the sample attended consultation regularly and for preventive reasons. This impact profile is expected to vary across different patient's clinical profiles and sociodemographical backgrounds. As for the OIDP and in accordance with other authors $(3,8)$, it was proved that the higher prevalence of impact appears when eating and also in hygiene dimensions. Logically, the impact recorded with the OHIP is higher than that published in a non-demanding Spanish population (3). Among the reasons collected through the OIDP these were the most important: pain, as also stated in the study made by Montero et al. (8) and Caglayan et al. (4) and teeth absence, as already shown by other authors (9). As regards the major reasons of impact in the OHIP, we found that aesthetics was the main cause behind the general patients' concern, while pain was the most common impact in the questionnaire, being responsible for the unpleasant sensations, general irritation, general difficulty and unsatisfactory life. The second most common cause was teeth absence, present in diet dissatisfaction, interruption of meals and disability in the development of ordinary life. 
General average satisfaction is healthy, although slightly lower than in non-demanding Spanish population (3). However, it became evident that the population takes more satisfaction from mastication than from aesthetics, as already stated by some authors $(9,10)$.

In our study, we have found that the higher the age, the more frequent the impacts, which might be explained by the accumulative kind of the oral pathology evaluated (tooth decay and periodontal disease), as already pointed out by other authors (11-13). Most clinical modulating factors have been previously reported (8-14), suggesting that caries, prosthetic conditions and periodontal status are closely related to OHQoL. As regards the gender, according to our results there are no significant differences, although there seems to be a marked tendency to higher impact and lower satisfaction in women. These data agree with other authors who state the independence of the variable gender $(8,15,16)$. As regards social class, despite the heterogeneity in the size of groups, the analysis of variance (ANOVA) revealed significant differences: subjects in the high class group had much more impact and less satisfaction than those in the middle or low class. The results agree with those gathered by McGracth et al. in their study conducted to 454 English people (15). For their part, David Locker et al. (16) and also Atchinson et al. (17) inform that the individuals of lower educational level refer more impact of their oral health in their quality of life. The place of residence also shows significant results, as in our study the people living in a rural environment revealed much more impact and less satisfaction than those living in urban areas. The finding might derive from matters of health education and accessibility to welfare services. Like in the Caglayan et al. study (4) the patients who attend consultation with periodontal problems revealed more impact and less satisfaction than those who didn't. Perhaps like Montero et al. (8) and Caglayan et al. (4) announced already dental pain is the main attack on well-being, having these patients the worst levels. The study suggests that a behavioural strategy (oral hygiene and regular visits) means a higher oral welbeing, which should be used to motivate patients to take a healthier attitude and have a better quality of life.

To summarize we conclude that the level of impact in dental patients is higher than the general Spanish population; patients who attend consultation in pain have worse well-being than those going for preventive, prosthetic or restorative reasons; the main modulating factors are age, social class, kind of residence, level of brushing, pattern of visits to the dentist, reason of consultation and clinical status.

\section{References}

1. Allison PJ, Locker D, Feine JS. Quality of life: a dynamic construct. Soc Sci Med. 1997;45:221-30.

2. Bravo M, Cortés J, Casals E, Llena C, Almerich-Silla JM, Cuenca E. Basic oral health goals for Spain 2015/2020. Int Dent J. 2009;59:7882 .

3. Montero-Martín J, Bravo-Pérez M, Albaladejo-Martínez A, Hernández-Martín LA, Rosel-Gallardo EM. Validation the Oral Health Impact Profile (OHIP-14sp) for adults in Spain. Med Oral Patol Oral Cir Bucal. 2009;14:E44-50.

4. Caglayan F, Altun O, Miloglu O, Kaya MD, Yilmaz AB. Correlation between oral health-related quality of life (OHQoL) and oral disorders in a Turkish patient population. Med Oral Patol Oral Cir Bucal. 2009;14:e573-8.

5. Adulyanon S, Vourapukjaru J, Sheiham A. Oral impacts affecting daily performance in a low dental disease Thai population. Community Dent Oral Epidemiol. 1996;24:385-9.

6. Slade GD. Derivation and validation of a short-form oral health impact profile. Community Dent Oral Epidemiol. 1997;25:284-90.

7. Locker D. Measuring oral health: a conceptual framework. Community Dent Health. 1988;5:3-18.

8. Montero J, Bravo M, Albaladejo A. Validation of two complementary oral-health related quality of life indicators (OIDP and OSS 0-10 ) in two qualitatively distinct samples of the Spanish population. Health Qual Life Outcomes. 2008;6:101.

9. Montero J, López JF, Galindo MP, Vicente P, Bravo M. Impact of prosthodontic status on oral wellbeing: a cross-sectional cohort study. J Oral Rehabil. 2009;36:592-600.

10. Payne BJ, Ford JC, Locker D. Loss to follow-up in a longitudinal oral health survey of older adults. Community Dent Oral Epidemiol. 1995;23:297-302.

11. Gift HC, Atchison KA, Dayton CM. Conceptualizing oral health and oral health-related quality of life. Soc Sci Med. 1997;44:601-8.

12. Locker D. Effects of non-response on estimates derived from an oral health survey of older adults. Community Dent Oral Epidemiol. 1993;21:108-13.

13. Dolan TA, Monopoli MP, Kaurich MJ, Rubenstein LZ. Oral diseases in older adults. J Am Geriatr Soc. 1990;38:1239-50.

14. MacEntee MI, Stolar E, Glick N. Influence of age and gender on oral health and related behaviour in an independent elderly population. Community Dent Oral Epidemiol. 1993;21:234-9.

15. McGrath C, Bedi R. A study of the impact of oral health on the quality of life of older people in the UK--findings from a national survey. Gerodontology. 1998;15:93-8.

16. Locker D, Slade G. Oral health and the quality of life among older adults: the oral health impact profile. J Can Dent Assoc. 1993; 59:830-3, 837-8, 844.

17. Atchison KA, Dolan TA. Development of the Geriatric Oral Health Assessment Index. J Dent Educ. 1990;54:680-7. 